\title{
Behavioral health screening and intervention for women in Argentina: a preliminary model for the childbearing years
}

REVIEW

This article was published in the following Dove Press journal:

International Journal of Women's Health

25 June 2015

Number of times this article has been viewed

\author{
Rocio M Suarez Ordoñez' \\ Jorgelina Cesolari ${ }^{2}$ \\ Casas Ofelia ${ }^{2}$ \\ Ivonne Villavicencio' \\ Hendrée E Jones ${ }^{3}$ \\ 'Research Department, Institute \\ of Cognitive Neuroscience INECO \\ Oroño, ${ }^{2}$ Neonatology Department, \\ Martin Maternity, Rosario, Santa Fe, \\ Argentina; ${ }^{3} \mathrm{UNC}$ Horizons and \\ Department of Obstetrics and \\ Gynecology, School of Medicine, \\ University of North Carolina at \\ Chapel Hill, Chapel Hill, NC, USA
}

Correspondence: Rocio M Suarez Ordoñez

Research Department, Institute of Cognitive Neuroscience INECO Oroño, Bv Oroño 1508 Rosario, Santa Fe, Argentina 2000

Tel +54 34l 4258695

Email rsuarezordonez@inecoorono.org

\begin{abstract}
Untreated behavioral disorders in pregnant women and in women of childbearing age pose physical and psychological safety concerns and are barriers to the well-being of both mother and neonate. The present paper underlines the importance of screening in Argentina for behavioral problems in women of childbearing age, particularly pregnant women and their newborns. Emphasized is the need to formalize this comprehensive screening in a protocol that includes domains of mental disorders, behavioral disorders, education, social environment, employment, desire for maternity, substance use including non-prescription use of prescription medications, eating disorders, suicide risk, interpersonal violence, stress, and trauma. Implementation of such a model would require agreement and cooperation between the public and private health sectors as well as in the development of research for validation of the various screening and interventions tools that would be adopted for general use.
\end{abstract}

Keywords: pregnancy, substance use, assessment, measures

\section{Introduction}

Women of childbearing age in Argentina face a myriad of challenges. The most important factors affecting their health during childhood and adolescence are: suicidal behavior, accidents, substance use, violence, and risky sexual behavior. ${ }^{1}$ In the population of women in Argentina, the average age of initiating tobacco and alcohol use is 13 years; while use of psychotropic drugs, solvents, inhalants, and "paco" (cocaine paste) is estimated to start at 14 years of age; and cocaine, ecstasy, and marijuana use typically begins at 15 years of age. ${ }^{2}$ This pattern of early substance use could be related to the exponential increase in suicides registered from 1997 to 2012 among women aged 15-29 years, which increased between $102 \%$ and $112 \%$ during this time period. Violence against women (gender violence) also escalated in Argentina in 2013, with a femicide (defined as a murder by a man of a woman he considers to be his property) occurring every 30 hours, resulting in 295 femicides in $2013 .{ }^{4}$ In terms of education, the percentage of youth completing secondary education is less than policy-makers in Argentina expected, resulting in less access to the labor market for youth, with women more affected by unemployment than men. ${ }^{5}$ Finally, but not surprisingly, the $21 \mathrm{st}$ century has witnessed a growth in teenage pregnancy rates. In 2001, the adolescent fertility rate was 30.5 per 1,000 women aged 10-19 years, while in 2011 this rate escalated to 35.3. ${ }^{6}$ Currently, in Argentina, "a girl, under 15 years of age, gives birth and becomes a mother of another boy or girl" every 3 hours. ${ }^{7}$

In Argentina, 300 women die annually from causes related to unsafe abortion, pregnancy, childbirth, and the puerperium. Unsafe abortions typically occur outside 
the health care system, often in unsanitary conditions, and are the result of restrictive national legislation regarding abortion. The complications of an unsafe abortion are the first direct obstetric cause of death, with $60 \%$ of unsafe abortions due to unplanned pregnancies. ${ }^{8}$ The high rate of unplanned pregnancies in the adolescent population not only increases the risk of exposure to unsafe abortion but also directly contributes to dropout from school, problems with personal development, behavioral problems, restricted access to the labor market, and substance use disorders, all of which have adverse consequences for both the mother and her child. Mother and infant can best be understood within the context of the mother's unique life circumstances, which include the mother's personal strengths and issues, external factors that exert pressures or limitations on her behavior, her support network, and the needs of the infant. ${ }^{9}$

Physical disorders and behavioral problems are seen by obstetric health care providers in Argentina as reflecting the operation of two parallel systems, rather than as a single interdependent system. However, this gap is starting to close due to implementation of the Perinatal Information System. ${ }^{10}$ The Perinatal Information System consists of a perinatal clinical record, a perinatal card, and a computerized program for processing of the information for each patient. This tool gathers information about the stages of the pregnancy, childbirth, the postpartum period, and characteristics of the newborn. It is intended to be implemented for patient follow-up. However, the need to screen for behavioral disorders is not yet fully recognized by obstetric providers, for three possible reasons. First, there is the continuing question among health care providers regarding the purposes of screening. Although there is some recognition of the need to screen, prejudice remains about: for what behavioral problems should women of childbearing age be screened; when best to screen for such problems; and how to screen. Second, there is a strong underlying implicit belief that the vast majority of behavioral problems in these women are due to social and economic issues that are outside the scope of obstetric care. Thus, providers may not recognize their responsibility regarding the need to care for the whole woman. Finally, there is the well-founded question of what exactly to do if screening for a behavioral problem is positive. As a result, most screening for behavioral problems is done by individual health care providers, who may lack the knowledge and experience to adequately screen for behavioral problems.

The aim of the present paper is to outline the importance of screening for behavioral problems and issues in pregnant women, in those of childbearing age, and in their newborns, and to offer a comprehensive and dynamic behavioral health screening model for this purpose that could be implemented in Argentina. Primary prevention with systematic obstetrics and gynecology visits represents continuing opportunities to screen patients for not only physical but also behavioral health issues. Assessment and treatment would then be provided for patients whose screening results are positive.

In the present context, the term behavioral health screening means the use of a formal screening procedure or protocol that includes screening in six overlapping areas of a woman's life: social functioning (eg, education, employment, social environment, social support), psychological functioning (eg, mental disorders, behavioral disorders, stress), substance use (licit and illicit substance use, including tobacco, alcohol, and misuse of prescription medication), suicide risk, exposure to trauma, and exposure to interpersonal violence.

\section{Social functioning}

Secure attachments, equitable relationships, feelings of love, and a lack of violence may be particularly important factors in improved mental and physical health during pregnancy. ${ }^{11}$ In Argentina, adolescent parenthood is more prevalent among youth in poor and less educated socioeconomic sectors. In 2013, of the total number of teenage pregnancies, $69 \%$ were unplanned pregnancies and $65 \%$ of the pregnant girls did not use any contraceptive method. ${ }^{12}$

\section{Psychological functioning}

The presence of behavioral disorders in the mother is a powerful risk factor for the safety and security of the mother-child relationship. ${ }^{13}$ However, the emphasis in the present paper on screening expands the focus on behavioral problems experienced by pregnant women and women of childbearing age to include the possibility of engaging in primary and secondary prevention, rather than more narrowly on behavioral disorders for which such women might be diagnosed and only tertiary prevention would be provided. Attempting to solve problems such as sustained substance use, interpersonal violence, and breastfeeding when its medically contraindicated, demands high economic and medical resources. Primary and secondary prevention, such as education in woman rights, pregnancy, consequences of substance use, early diagnosis, and use of referral services, are considered key factors to help avoid these issues.

\section{Substance use}

Although many obstetric patients have first-hand experience with substance use, they often lack accurate information 
about both licit (notably tobacco and alcohol, as well as inhalants) and illicit (notably methamphetamines and cocaine) substances, their effects, and their health consequences for mother, fetus, and neonate. ${ }^{9}$ Education before and during pregnancy regarding use of substances that are deleterious to the mother and fetus is essential. Providers also need education regarding how to help such women during a prenatal care visit. ${ }^{14}$

\section{Suicide risk}

Suicide risk is highest for young women aged 15-19 years. The suicide rate in this age group has experienced an increase of $57 \%$ from 1997 to $2009 .{ }^{15}$ Due to personalities that are often more unstable and impulsive, adolescents are a vulnerable group with the highest rate of suicides. ${ }^{16}$ In addition, teenage girls may be particularly affected by situations of physical, sexual and/or emotional abuse, eating disorders, alcohol and illicit substance use, maturation processes, and construction of a sexual identity. ${ }^{15}$

\section{Trauma}

The brain develops in ways that reflect the influence of early exposure to environmental events such as sensory stimuli, drugs, diet, hormones, and stress. Early interpersonal experiences affect both gene expression and brain architecture, which can influence a wide range of behaviors in adulthood. ${ }^{17}$ Adverse childhood experiences, such as maltreatment, instability in the home, or family problems, can lead to complex psychological and physical adaptations during both childhood and adulthood. Post-traumatic stress disorder related to childhood trauma is associated with significant subsequent deficits in regulation of emotion, interpersonal functioning, and an impaired sense of self. ${ }^{18}$

\section{Interpersonal violence}

The environmental stress of intimate partner violence is common and often results in mental health problems of depression, anxiety, and post-traumatic stress disorder for women of childbearing age and behavioral disorders for their children. ${ }^{19}$

\section{Preliminary comprehensive behavioral health screening and intervention model}

Figure 1 presents a flowchart of our comprehensive behavioral health screening and intervention model. The first premise underlying this chart is continuity. The patient's initial screening will then trigger subsequent medical, social, and/or psychological follow-up screenings. In this context, screening should be understood to be comprehensive and include a medical history, and information regarding patient level of education, socioeconomic situation, living conditions, family composition, traumatic situations, mental health, personal health factors such as tobacco, alcohol, and illicit substance use, misuse of prescription medications, and the perception of risk of substance use. The second premise is engagement. Screening should be conducted by professionals familiar with appropriate methods of screening. This is so for two reasons, ie, to avoid incomplete screening and patients not returning to treatment. When screening is conducted in communities with vulnerable populations, trust between the patient and the health care provider is essential. Eye contact, appropriate body language, and active listening are key factors above and beyond explanation of the need for screening. This leads to the third premise, ie, that the patient should be provided, during screening and, if necessary, in treatment, with a health care professional as the primary contact for the purposes of both referral and follow-up.

For pregnant women, screening would also include sources of both prenatal and postnatal support, include social and familial, presence and involvement of the father, and plans for the infant following delivery (eg, adoption, home life with the mother). An impoverished socioeconomic environment may contribute to abuse and neglect through both lack of knowledge regarding acceptable child-rearing practices and increased parental stress. ${ }^{20}$ Screening for use of both licit and illicit substances would also need to be conducted. Particular attention should be given to substances that may not prove detrimental to the mother in the short-term but have pronounced adverse impacts on the fetus, notably alcohol and tobacco. It is important to note that, from 2004 to 2010 , substance use in Argentina has increased among both women and men, especially between the ages of 16 and 24 years. ${ }^{21}$ A pregnant woman with a substance use disorder is exposed not only to the adverse effects of the substance(s) on herself and her child, but also to the increased risk of gender-based violence from her partner, and difficulties in establishing an emotional bond with her newborn due to possible antisocial maternal behavior, depression, and anxiety. ${ }^{20,22,23}$ Moreover, a child with one or both parents with a substance use disorder has an increased risk of abuse and neglect.

From the viewpoint of the need for comprehensive screening of pregnant women, it is also the case that newborn screening is critically important. The perinatal death rate in Argentina is $12.3 \% .{ }^{24}$ However, the percentage of preventable deaths during the neonatal period climbs to $67 \%$. 


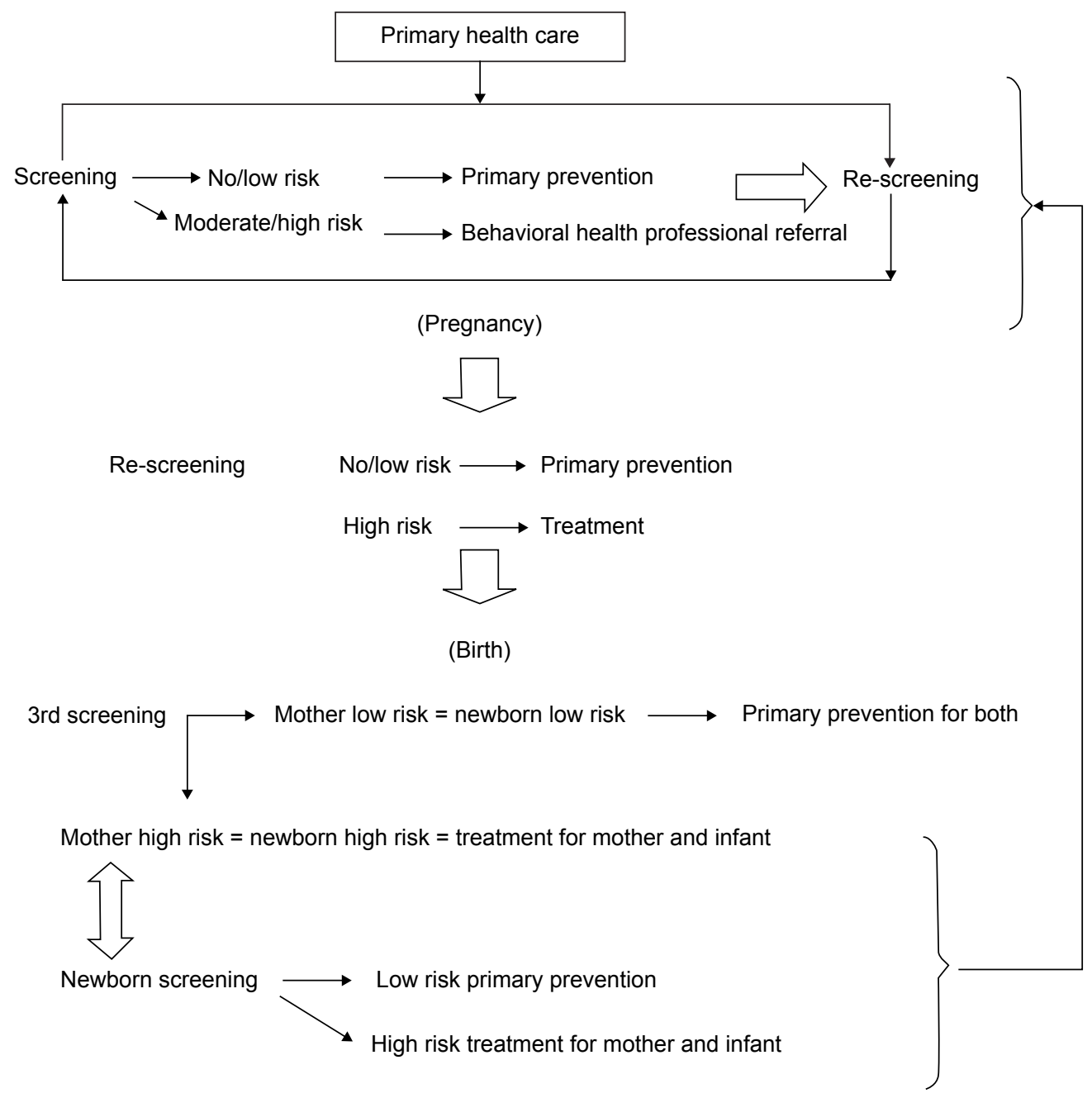

Figure I Comprehensive behavioral health screening and interventional model for women of childbearing age.

This increase would be related not only to health and nursing conditions and access, but also to the social and environmental conditions in which the lives of many children develop. ${ }^{14}$ Substance use during pregnancy poses complex challenges, as there is a multiplicity of biological and psychosocial factors that could act as moderators or mediators of the effects of substances on the fetus. Fetal programming refers to nongenetic factors such as unfavorable intrauterine conditions which can permanently organize physiological or behavioral systems in the fetus that alter normal development. According to this viewpoint, substance use during pregnancy may cause significant changes in the regulation of several genes during gestation, leading to clinically observable changes in the newborn. ${ }^{25}$

All infants and young children with suspected or confirmed exposure to maternal licit or illicit substance use in utero need to be closely evaluated for developmental delays in order to provide early and timely treatment. Of particular concern would be the assessment of neonatal abstinence syndrome in neonates exposed in utero to opioids. A number of drugs are thought to cause neonatal abstinence syndrome, including benzodiazepines, amphetamines, cocaine, alcohol, and barbiturates. However, opioids (heroin, methadone, morphine, codeine, buprenorphine) are the most frequent cause. Failure to adequately treat neonatal abstinence syndrome can lead to significant infant morbidity and mortality.

Substance use by a pregnant woman leads to alterations in maternal health, which combined with psychosocial problems often associated with such use as well as insufficient prenatal care, can result in deterioration of the health of the fetus and the dyad. Thus, assessment for a possible history of tobacco, alcohol, and substance use would need to be included routinely in the first contact with every patient. The health provider would also need to identify risk factors for such use in pregnant and non-pregnant women. If there is evidence of such exposure, intervention would begin immediately; the 
health provider should provide preliminary advice on risk reduction, and in many cases this advice should be coupled with an interdisciplinary consult including a mental health professional and/or social worker, and if necessary, specific referral to treatment programs that provide services for licit or illicit substance abuse and/or violence.

Table 1 summarizes the screening tools to be considered for the behavioral health problems discussed in this paper. These measures would provide a comprehensive screening of the patient's physical and psychological health during the first obstetric visit as well as screening for several possible risk factors.

\section{Licit drugs}

Tobacco

The Fagerström test of nicotine dependence is a six-item self-reported smoking screening tool in use worldwide. It is particularly sensitive to nicotine withdrawal symptoms and provides accurate guidance regarding treatment. ${ }^{26}$

\section{Alcohol}

The Alcohol Use Identification Test (AUDIT), a ten-item self-report and interview measure, has shown high sensitivity and specificity in Argentina. ${ }^{27}$ As appropriate use of time in the screening process is essential, both the TWEAK and the CAGE questionnaires are also appropriate as measures of alcohol use since they are very brief measures. In addition, the TWEAK was originally developed for use in prenatal populations. ${ }^{28}$

\section{Illicit substance use}

The Alcohol, Smoking and Substance Involvement Screening Test (ASSIST), developed for the World Health Organization, is a comprehensive measure of licit and illicit consumption. However, it requires a trained interviewer and, if the respondent has used a variety of substances, can be time-consuming. ${ }^{29}$

\section{Mental disorders}

The complexity of mental disorders and their possible comorbidity considerably complicates the process of assessment. The Modified MINI Screen is a 22-item screening interviewer-administered measure that takes approximately 10-15 minutes to complete. ${ }^{30}$ The M.I.N.I Plus is a more detailed version than the Modified MINI Screen but necessarily takes more time to administer. The Modified MINI Screen explores those symptoms that are better explained by a medical cause or use of alcohol and illicit drugs. ${ }^{31}$

\section{Depression}

The Beck Depression Inventory II is a 21-item self-report pencil-and-paper tool that provides a measure of the presence and severity of depression in adults and adolescents in primary care settings. ${ }^{32}$ For pregnant woman, the Patient Health Questionnaire- 9 may be the measure of choice. ${ }^{33}$ The moderate risk cutoff score identifies women with subdiagnostic symptom levels who may benefit from interventions to alleviate their distress and improve their pregnancy outcomes. The Patient Health Questionnaire-9 provides cutoff scores for "minimal symptoms", "minor depression", and "major depression". ${ }^{34}$

\section{Postpartum depression}

The Edinburgh Postnatal Depression Scale would be the measure of choice because it is an instrument specific to the postpartum period that is widely used in current studies in the field of maternal and child health, especially in Anglo populations, and has been found to be particularly useful in both research and clinical practice. ${ }^{35}$ The Edinburgh Postnatal Depression Scale has been validated in Spanish. ${ }^{36}$

\section{Suicide risk}

The Suicide Behaviors Questionnaire-Revised seems to be the most appropriate instrument, since it provides a complete screen of suicide risk in a brief four-item measure. ${ }^{37}$

\section{Stress}

Stress prepares the organism for action, allowing it to adapt to changes in the environment; however, when these demands become excessive and sustained over time, pathological stress can present. The Perceived Stress Scale, is a self-report measure with both four-item and ten-item versions, with extensive international reliability and validity. Research in Argentina with this scale has been limited. ${ }^{38}$

\section{Trauma}

The abbreviated Post-Traumatic Stress Disorder ChecklistCivilian was developed specifically for screening patients in primary care settings. The Life Events Checklist, because it is a lifetime measure, could provide additional information to better understand the historical records of the patients. ${ }^{39}$

\section{Interpersonal violence}

Gender violence must be addressed in primary care settings. The Spanish version of the Woman Abuse Screening Tool was found to be highly reliable, with a Cronbach level of $0.91 .{ }^{40}$ The Woman Abuse Screening Tool and the Abuse Assessment Screen have conceptualized intimate partner violence 


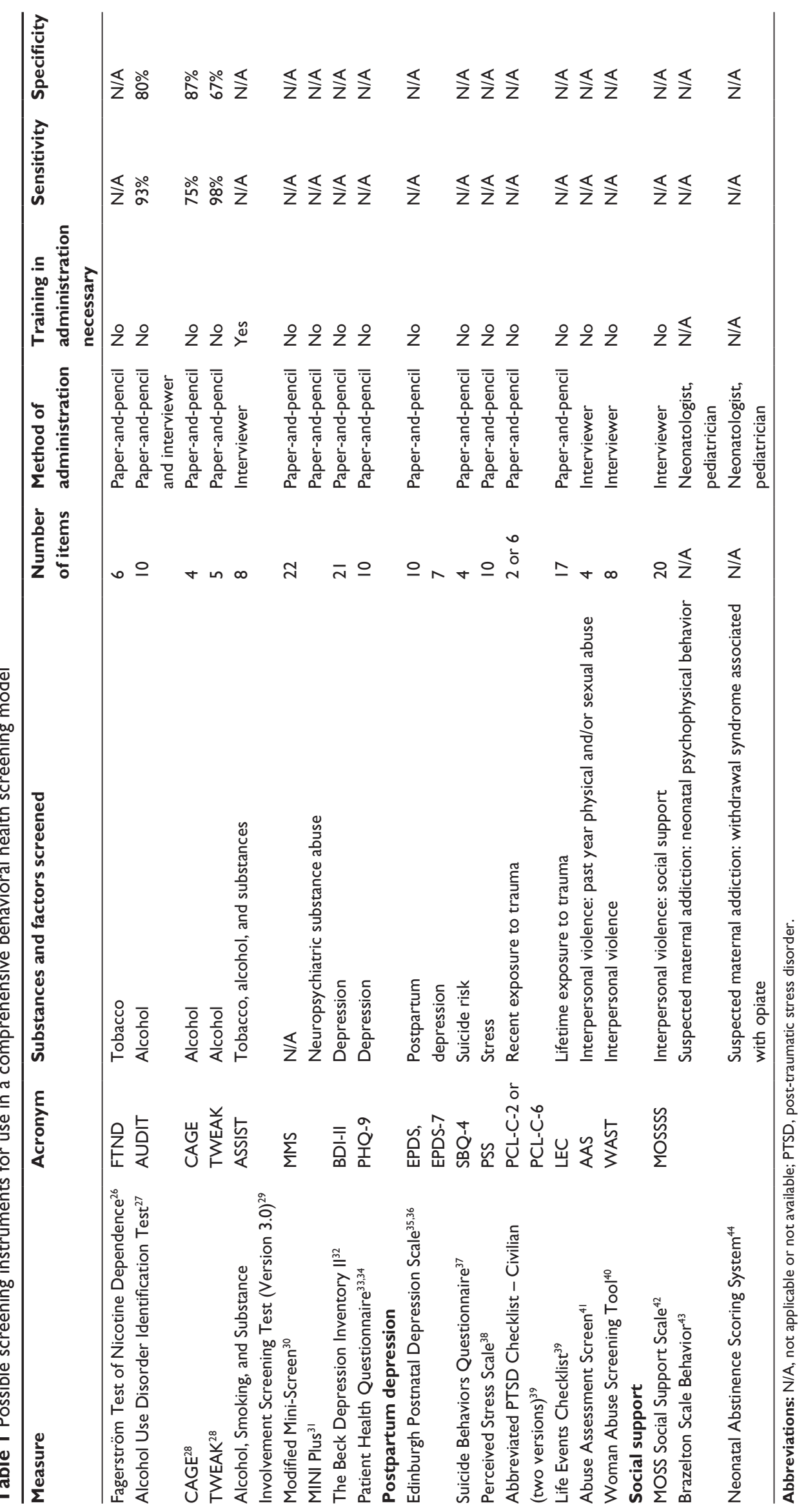


most broadly, including physical, emotional, and sexual violence as well as threats/fear. ${ }^{41}$ The Abuse Assessment Screen might be more appropriate for pregnant women.

\section{Social support}

The Medical Outcomes Study Social Support Scale includes 20 self-reported items that evaluate four dimensions of support, ie, emotional/informational, instrumental, positive social interaction, and affective. This scale has been found to be a valid and reliable instrument for measuring social support and to detect situations of social risk. ${ }^{42}$

\section{Newborn screening}

The Neonatal Behavioral Assessment Scale (NBAS; often called the Brazelton scale) can be used to assess early infant development and examines a broad range of neonatal behaviors during the period shortly after birth until 2 months of age. The NBAS is one of the single most comprehensive measures of the development of behavior in newborns. ${ }^{43}$ However, the NBAS requires a trained examiner who provides a comprehensive assessment of the infant, including relative strengths and weaknesses.

The Neonatal Abstinence Scoring System, often referred to as the Finnegan method or the Finnegan scoring system, which uses trained raters to assess the degree of withdrawal associated with opioids, can be quite useful in both determining an early diagnosis of neonatal abstinence syndrome, progress on treatment, and the neonate's response to treatment. ${ }^{44}$

The Neonatal Intensive Care Unit (NICU) Network Neurobehavioral Scale (NNNS) was developed as an assessment tool for at-risk infants. ${ }^{45}$ Such infants could present an increased risk for poor developmental outcome because of substance exposure, prematurity, or factors such as poverty, poor nutrition, or lack of prenatal care. The NNNS assesses the full range of infant neurobehavioral performance, including neurological integrity, behavioral functioning, and signs of stress/abstinence. ${ }^{46}$ However, the NNNS requires a trained examiner, so likely should be reserved for neonates in whom there is a strong suspicion of risk of neurodevelopmental problems.

Finally, unless otherwise noted, in Argentina there is no reliability or validity information for some of the screening instruments noted in Table 1, which provides an opportunity for future research.

\section{Referral for assessment and treatment}

Knowledge and clear information on how to respond to a positive screening for substance use is extremely important.
The health provider needs to be aware of the different treatment options available or be able to transfer the patient to a colleague or agency who can provide the needed services. On the one hand, if the patient has no social or prepaid health insurance, and is covered by the state, it would be necessary to refer the patient to a public treatment agency in the patient's district and follow-up to ensure that the patient was able to receive the needed treatment. On the other hand, if the patient has health insurance, whether social or prepaid, it would be necessary to determine which private treatment agency works with each specific insurance carrier and the conditions of the coverage. These actions could help to overcome the obstacles often encountered by women navigating a complex health system in search of treatment, which often results in patients foregoing further treatment.

It is crucial that the patient understands the reasons for the referral. The health provider should involve the patient in the process of treatment-seeking, encourage her interest in treatment, and thereby its success.

\section{Current limitations to behavioral health screening and implementation}

There are some limitations at present that could serve to reduce the effectiveness of screening and interventions. None are limitations unique to our comprehensive behavioral health screening and intervention model, and all can be effectively addressed, although success would require changes in such factors as insurance coverage, new legislation, and importantly, changes in the attitudes and behaviors of health care providers.

The screening process takes time and resources would need to be sustained on multiple levels, including not only on the part of the health provider but also on the part of the agencies underwriting the costs of such screening. The scope of the screening tool may be seen as overly broad; however, its breadth ensures the provider may facilitate care of all aspects of the woman - her physical, mental, and social well-being. There are minimal national screening policies for substance use. Hence, this issue needs to be considered by the National Ministry of Health in a timely manner, in order to move the process forward. Furthermore, social education regarding screening as a preventive and noninvasive method is essential. This would avoid resistance on the part of patients toward some potentially sensitive aspects of the screening model outlined.

The reliability and validity of screening instruments is a very important matter to be addressed in order to implement our screening model. Currently, Argentina has no instruments available to screen for substance abuse, trauma, or violence, especially in pregnant women and women of childbearing 
age. Argentina has experienced deep social changes in the past 25 years, resulting in new ways of social interaction and producing increases in drug use, urban gangs, genderbased violence, and a deep socioeconomic divide between the lower and upper economic segments of the population. It would be appropriate for these social changes to be taken into account when validating or developing screening and intervention instruments.

\section{Conclusion}

Behavioral disorders in pregnant women and in women of childbearing age remain a major public health and security concern for both mother and neonate. The present paper underlines the importance of screening for behavioral problems in women of childbearing age, particularly pregnant women and their newborns, and emphasizes the need to formalize screening in a protocol that includes screening for mental disorders, behavioral disorders, education, social environment, employment, desire for maternity, non-prescription use of prescription medications, eating disorders, suicide risk, interpersonal violence, stress, and trauma. Women with behavioral problems pose a threat to their own health and that of their newborn. It is not only life that reproduces, but behavior.

Widespread implementation of screening would require a state policy that targets every pregnant and childbearingage woman in Argentina. This implementation would require recognition of the importance of screening for behavioral disorders and its solutions at the individual, social, economic, and political levels. Implementation of the model would also require agreement and cooperation between the public and private health sectors as well as in the development of research for validation of the various screening and interventions tools that would be adopted for general use.

\section{Disclosure}

The authors report no conflicts of interest in this work.

\section{References}

1. Bella M. [Risk behaviors for health in children and adolescents with suicide attempts and in their families]. Rev Med Chil. 2012;140: 1417-1424. Spanish.

2. Observatorio Argentino de Drogas. Tendencia en el consumo de sustancias psicoactivas en Argentina 2004-2010. [Tendency to psychoactive substance in Argentina 2004-2010]. Available from: http://www. observatorio.gov.ar/investigaciones/Tendencia_en_el_consumo_20042010_Poblacion_General_v3.pdf. Accessed July 21, 2014. Spanish.

3. Asociacion de Politicas Publicas. Homiciios y suicidios en Argentina: Alcances y evolución de 1997 a 2012. [Homicides and suicides in Argentina: scope and evolution 1997 to 2012]. Available from: http:// www.app.org. ar/wp-content/uploads/2014/09/Homicidios-y-Suicidiosen-Argentina2014.pdf. Accessed June 30, 2014. Spanish.
4. Observatorio de Femicidios en Argentina. Informe de investigación sobre femicidios en Argentina. 1er de Enero al 31 de Diciembre 2013. [Research report on femicide in Argentina January 1 to December 31, 2013]. Available from: http://www. lacasadelencuentro.org/femicidios. html. Accessed July 30, 2014. Spanish.

5. Area de Desarrollo Social. Recomendaciones integrales de política pública para las juventudes en la Argentina. [Comprehensive public policy recommendations for youths in Argentina]. Available from: http://www.cippec.org/documents/10179/51825/137+DPP+PS, $\% 20$ Recomendaciones+integr ales + de + po $1 \%$ C $3 \%$ ADtica + p $\%$ C3\%BAblica + para + las + juventudes + en + la + Argentina, $\% 20$ Repetto+y+Diaz+Lango, \%202014+.pdf/deb901c9f9ed-470e-886d7200de5f4829. Accessed October 21, 2014. Spanish.

6. Unicef. Situación del embarazo adolescente en Argentina, en el día mundial de la población [Situation of teenage pregnancy in Argentina]. Available from: http://www.unicef.org/argentina/spanish/Embarazo adolescente_Argentina-VB.pdf. Accessed July 28, 2014. Spanish.

7. ASUMEN. En nuestro país, cada 3 horas, una niña da a luz y se convierte en madre de otro niño. [In our country, every 3 hours, a girls gives birth and become a mother of another boy or girl]. Available from: http://www.unicef.org/argentina/spanish/ASUMEN_ALERTA_embarazo_menores_15_Mayo2014.pdf. Accessed July 25, 2014. Spanish.

8. Observatorio de Salud Sexual y Reproductiva. La situación de la mortalidad materna en Argentina y el desarrollo del Milenio, Meta 5. [The situation of maternal mortality in Argentina and the Millennium Development Goal 5]. Available from: http://www.ossyr.org.ar/pdf/ hojas_informativas/hoja_8.pdf. Accessed July 30, 2014. Spanish.

9. Jones H, Kaltenbach K. Treating Women with Substance Use Disorders During Pregnancy. 1st ed. New York, NY, USA: Oxford University Press; 2013.

10. Mainero L, Martínez G, Rubino M, De Mucio B, Diaz Rossello JL, Fescina R. Perinatal Information Systems manual for use of the program for the analysis and advantage of the information. Pan American Health Organization, World Health Organization Latin American Perinatology Center, Women's Reproductive Health; 2010. Available from: http://www.clap.ops-oms.org/sistemas/programas/CLAP1565-02.pdf. Accessed May 9, 2015.

11. Kershaw T, Murphy A, Divney A, Magriples U, Niccolai L, Gordon D. What's love got to do with it: relationship functioning and mental and physical quality of life among pregnant adolescent couples. J Environ Public Health. 2014;52(3-4):288-301.

12. Observatorio de Salud Sexual y Reproductiva. Embarazo adolescente. [Pregnancy in adolescence]. Available from: http://www.ossyr.org. ar/pdf/hojas_informativas/hoja_10.pdf. Accessed August 2, 2014. Spanish.

13. Quezada V, Santelices MP. Apego y psicopatología materna: relación con el estilo de apego del bebé al año de vida. [Attachment and mother's psychopathology: relationship with baby attachment style in the first year of life]. Rev Lat Am. 2009;42:53-61. Spanish.

14. United Nations Children's Fund. Salud materno-infanto-juvenil en cifras. [Maternal and child and adolescent health in figures 2013]. Available from: http://www.unicef.org/argentina/spanish/salud_SapUnicef_cifras2013.pdf. Accessed October 21, 2014. Spanish.

15. Asociacion de Politicas Públicas. Mapa de la violencia de género en Argentina. [Map of gender violence in Argentina]. Available from: http://www.app.org.ar/wp-ontent/uploads/2011/12/MapadeViolenciadeGeneroenArgentina1.pdf. Accessed August 1, 2014. Spanish.

16. Bridge JA, Goldstein TR, Brent DA. Adolescent suicide and suicidal behavior. J Child Psychol Psychiatry. 2006;47(3-4):372-394.

17. Attridge M, Ghali L. Linking early brain and biological development to psychiatry: introduction and symposia review. J Can Acad Child Adolesc Psychiatry. 2011;20(4):253-264.

18. Lanius RA, Vermetten E, Pain C, editors. The Impact of Early Life Trauma on Health and Disease: The Hidden Epidemic. 1 st ed. New York, NY, USA: Cambridge University Press; 2010.

19. Maddoux J, Symes L, McFarlane J, et al. An abbreviated PTSD checklist for use as a screening instrument in primary care. Behav Res Ther. 2005;43(5):585-594. 
20. Pajer KA, Gardner W, Lourie A, Chang CN, Wang W, Currie L. Physical child abuse potential in adolescent girls: associations with psychopathology, maltreatment, and attitudes toward child-bearing. Can J Psychiatry. 2014;59(2):98-106.

21. Observatorio Argentino de Drogas. [Trends in psychoactive substance consumption]. Available from: http://www.observatorio.gov.ar/ investigaciones/Tendencia_en_el_consumo_2004-2010_Poblacion_ General_v3.pdf. Accessed July 2, 2014.

22. De Paul J, Domenech L. Childhood history of abuse and child abuse potential in adolescent mothers: a longitudinal study. Child Abuse Negl. 2000;24(5):701-713.

23. Kim-Cohen J, Caspi A, Rutter M, et al. The caregiving environments provided to children by depressed mothers with or without an antisocial history. Am J Psychiatry. 2006;163(6):1009-1018.

24. Ministerio de Salud. Indicadores básicos. [Basic indicators Argentina 2014]. Available from: http://www.paho.org/arg/images/gallery/indicadores/indicadores_2014_opsarg.pdf?ua=1. Accessed November 25, 2014. Spanish

25. Jansson L, Velez M. Infants of drug dependent mothers. Pediatr Rev. 2011;32(1);5-13.

26. Heatherton TF, Kozlowski LT, Frecker RC, Fagerström KO. The Fagerström test for nicotine dependence: a revision of the Fagerström Tolerance Questionnaire. Br J Addict. 1991;86(9):1119-1127.

27. World Health Organization. The Alcohol Use Disorders Identification Test: guidelines for use in primary health care. Geneva, Switzerland: World Health Organization; 1992. Available from: http:/whqlibdoc. who.int/hq/1992/who_psa_92.4.pdf. Accessed May 8, 2015.

28. Cremonte M, Ledesma R, Cherpitel C, Borgues G. Psychometric properties of alcohol screening test in the emergency department in Argentina Mexico and the United States. Addict Behav. 2010;35(9):818-825.

29. World Health Organization, ASSIST Working Group. The Alcohol, Smoking and Substance Involvement Screening Test (ASSIST): development, reliability and feasibility. Addiction. 2022;97(9):1183-1194.

30. New York State Office of Alcoholism and Substance Abuse Services Screening for co-occurring disorders using the Modified Mini Screen (MMS): User's Guide, 2005. Available from: www.oasas.ny.gov/treatment/COD/.../MINIScreenUsersGuide.pdf. Accessed May 8, 2015.

31. Sheehan DV, Lecrubier Y, Sheehan KH, et al. The Mini-International Neuropsychiatric Interview (M.I.N.I.): the development and validation of a structured diagnostic psychiatric interview for DSM-IV and ICD-10. J Clin Psychiatry. 1998;59 Suppl 20:22-33.

32. Arnau RC, Meagher MW, Norris MP, Bramson R. Psychometric evaluation of the Beck Depression Inventory-II with primary care medical patients. Health Psychol. 2001;20(2):112-119.

33. Kroenke K, Spitzer RL, Williams JB. The PHQ-9: validity of a brief depression severity measure. J Gen Intern Med. 2001;16(9):606-613.

34. Sidebottom AC, Harrison PA, Godecker A, Kim H. Validation of the Patient Health Questionnaire (PHQ)-9 for prenatal depression screening. Arch Womens Ment Health. 2012;15(5):367-374.
35. Maroto Navarro G, Garcia Calvente M, Fernández Parra A. Evaluación del estado de ánimo en el puerperio con la Escala de Depresión Postnatal de Edimburgo. [Evaluation of mood in the postpartum period with the Edinburgh Postnatal Depression Scale]. Int J Clin Health Psychol. 2005;5(2):305-318. Spanish.

36. Mathisen SE, Glavin K, Lien L, Lagerløv P. Prevalence and risk factors for postpartum depressive symptoms in Argentina: a cross-sectional study. Int J Womens Health. 2013;5:787-793.

37. Osman A, Bagge CL, Gutierrez PM, Konick LC, Kopper BA, Barrios FX. The Suicidal Behaviors Questionnaire-Revised (SBQ-R): validation with clinical and nonclinical samples. Assessment. 2001;8(4): $443-454$.

38. Cohen S, Kamarck T, Mermelstein R. A global measure of perceived stress. J Health Soc Behav. 1983;24(4):385-396.

39. Lang AJ, Stein MB. An abbreviated PTSD checklist for use as a screening instrument in primary care. Behav Res Ther. 2005;43(5):585-594.

40. Colleen T, Fogarty MD, Brown J. Screening for abuse in Spanishspeaking women. J Am Board Fam Pract. 2002;15(2):101-111.

41. Rabin RF, Jennings JM, Campbell JC, Bair-Merritt MH. Intimate partner violence screening tools: a systematic review. Am J Prev Med. 2009; 36(5):439-445.

42. Rodriguez Espinola S, Enrique S, Carmelo H. Validación Argentina del cuestionario MOS de apoyo social percibido. [Validation of Argentinian Social Support Scale (MOS)]. Available from: http:/www.palermo.edu/ cienciassociales/publicaciones/pdf/Psico7/7Psico\%2010.pdf. Accessed May 9, 2015. Spanish.

43. Medina JPL, Ospina Díaz JM, Abril FGM. Propiedades psicométricas de la escala NBAS aplicada a recién nacidos prematuros o con bajo peso. [Psychometric properties of the NABS scale applied to preterm or low birthweight]. Revista Ciencias de la Salud. 2012;10(1):43-58. Spanish.

44. Pérez A. Guias de tratamiento unidad cuidados intensivos neonatal, hospital San Juan de Dios; Hijo de madre adicta a drogas. 2012. Cap 16, 123-128, La Serena Chile, año 2012. [Treatment guidelines neonatal intensive care unit, hospital San Juan de Dios; baby of mother addicted to drugs. 2012. Chapter 16]. Available from: http://www.manuelosses. cl/BNN/gpc/Guias\%20NN\%20La\%20Serena_2012.pdf. Accessed June 21, 2014. Spanish

45. Tronik E, Lester BM. Grandchild of the NBAS: the NICU Network Neurobehavioral Scale (NNNS). A review of the research using the NNNS. J Child Adolesc Psychiatr Nurs. 2013;26(3):193-203.

46. Lester BM, Andreozzi-Fontaine L, Tronick E, Bigsby R. Assessment and evaluation of the high risk neonate: the NICU Network Neurobehavioral Scale. J Vis Exp. 2014;(90).
International Journal of Women's Health

\section{Publish your work in this journal}

The International Journal of Women's Health is an international, peerreviewed open-access journal publishing original research, reports, editorials, reviews and commentaries on all aspects of women's healthcare including gynecology, obstetrics, and breast cancer. The manuscript management system is completely online and includes

\section{Dovepress}

a very quick and fair peer-review system, which is all easy to use. Visit http://www.dovepress.com/testimonials.php to read real quotes from published authors. 